\title{
Novel inorganic-organic hybrid block copolymers as pore generators for nanoporous ultra-low-dielectric films
}

Hyun Wook Ro ${ }^{\mathrm{a}}$, Kook Ji Kim ${ }^{\mathrm{a}}$, Patrick Theato ${ }^{\mathrm{b}}$, David W. Gidley ${ }^{\mathrm{c}}$, and Do Y. Yoon ${ }^{\mathrm{a} *}$ 


\section{Supporting information:}

Representative NMR spectrum of a hybrid block copolymer.

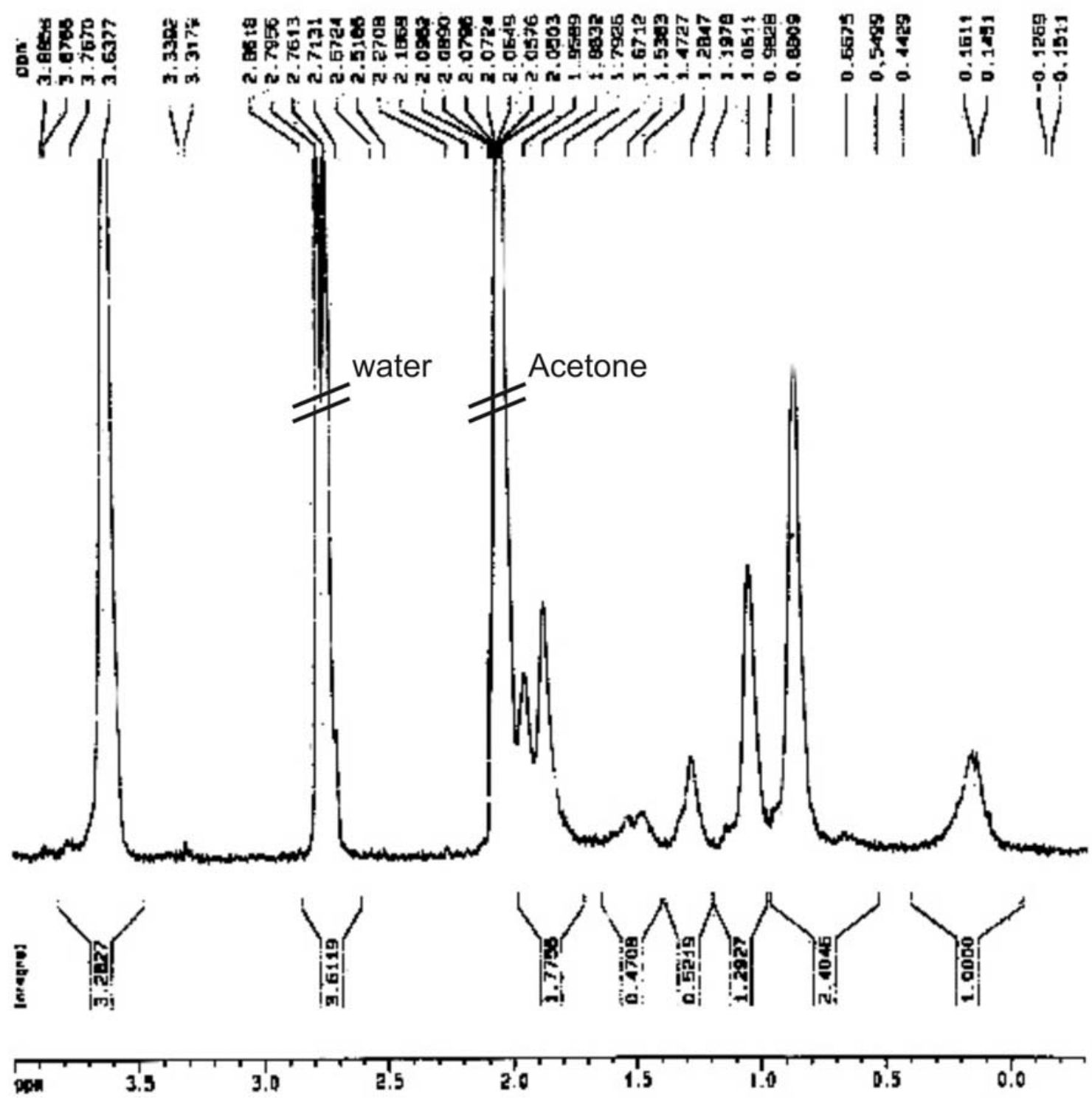


- GPC trace of the hybrid copolymer, as compared with that of PMSSQ

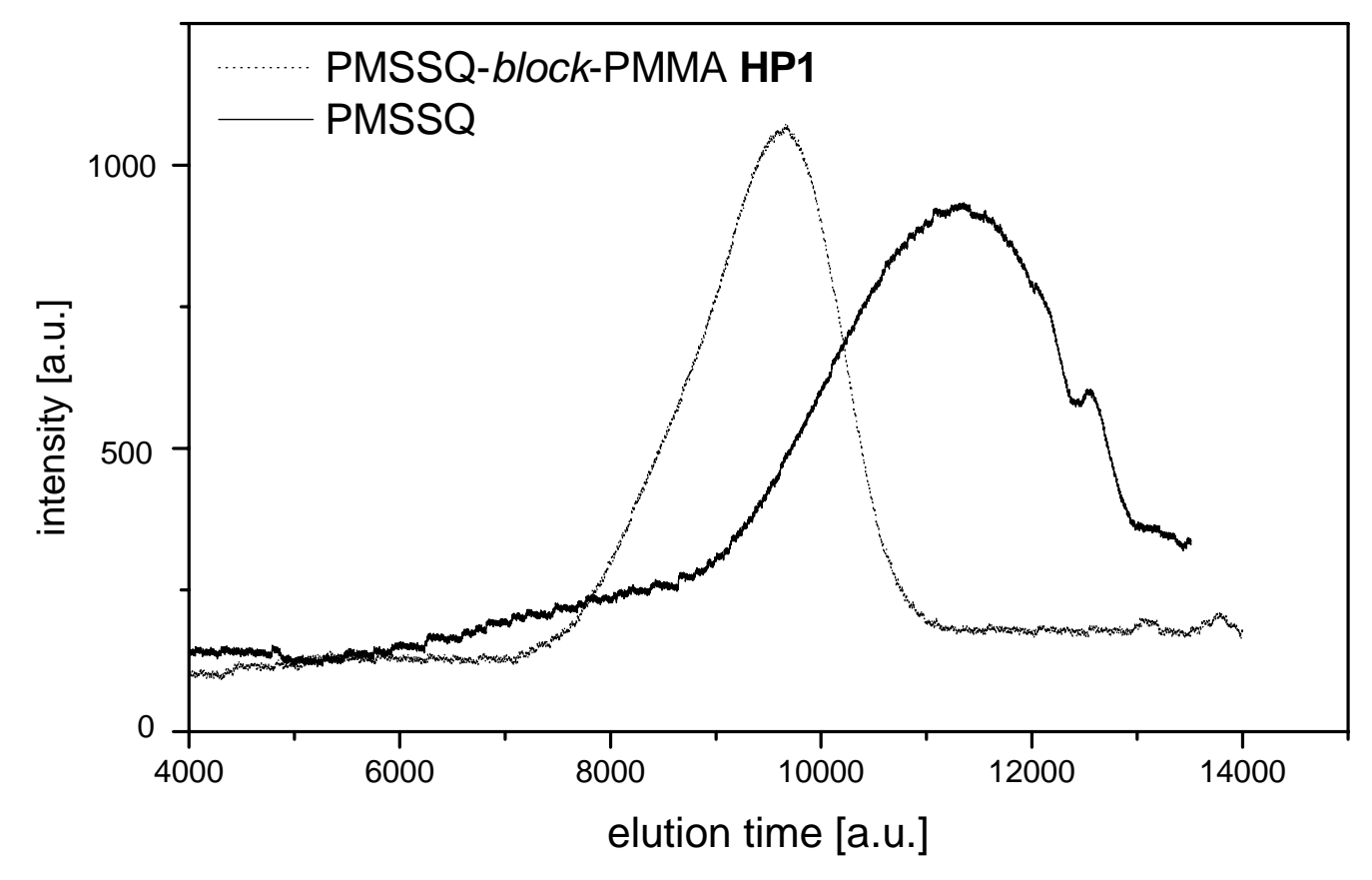


Representative DSC heating curves of PMMA homopolymer and PMSSQ- $b$-PMMA (HP1) hybrid block copolymers, showing that the glass transition temperature of the PMMA block in the copolymer is practically identical to that of PMMA homopolymer.

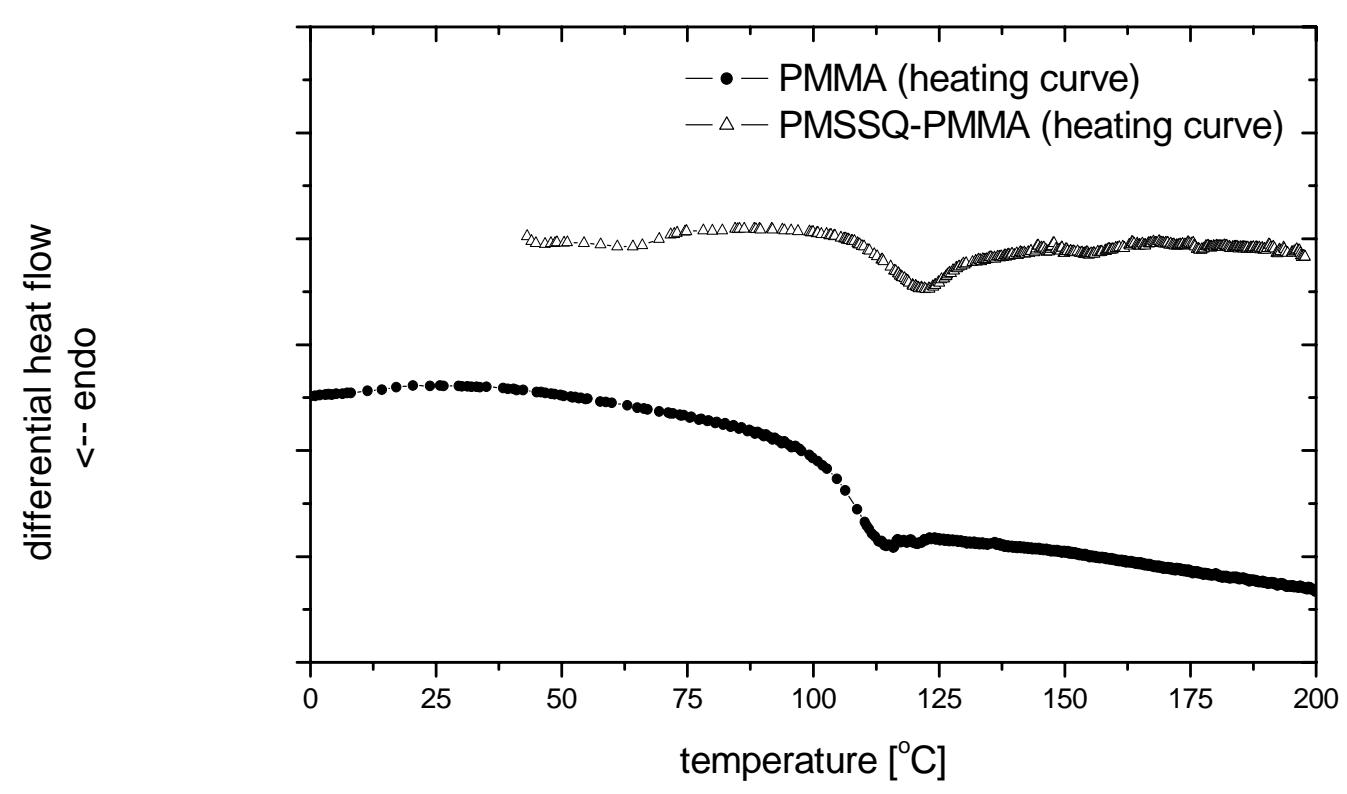




\section{Experimental Section}

Materials. All chemicals were commercially available and were used without further purification unless otherwise stated. Methyl methacrylate (MMA) was distilled under reduced pressure. THF was distilled from sodium/benzophenone under nitrogen. Toluene was distilled from sodium/benzophenone under nitrogen. $\mathrm{CuBr}$ was purified by stirring for 24 hrs with acetic acid, filtered off, washed with methanol and dried in vacuum.

Characterization. All ${ }^{1} \mathrm{H}$ and ${ }^{13} \mathrm{C}$ NMR were recorded on a Bruker DPX-300 MHz NMR spectrometer. Gel permeation chromatography (GPC) was performed with a house-made GPC equipped with a bed Jordi column and Waters 2410 differential refractometer. THF was used as an eluent at a flow rate of $1.0 \mathrm{~mL} / \mathrm{min}$ and the column was calibrated with polystyrene standards (Polymer Standard Service, USA Inc.) which range from 500 1.000.000 in molecular weight. The glass-transition temperatures were determined using a TA Instruments differential scanning calorimeter (2910 DSC). Samples were heated with a heating rate of $10{ }^{\circ} \mathrm{C} / \mathrm{min}$ in a nitrogen atmosphere. Thermogravimetric analysis (TGA) was carried out on a TA instruments under nitrogen atmosphere at a heating rate of $10{ }^{\circ} \mathrm{C} / \mathrm{min}$. The samples were first heated to $100{ }^{\circ} \mathrm{C}$, kept at this temperature for one hour and were then heated to $500{ }^{\circ} \mathrm{C}$. All the nanoporous thin film samples were prepared by spin-coating MIBK solutions on silicon wafers and curing successively for 1 hr at $130{ }^{\circ} \mathrm{C}, 250{ }^{\circ} \mathrm{C}$, and $430{ }^{\circ} \mathrm{C}$, respectively. The Refractive index and thickness of thin films were measured with a variable-angle multi-wavelength ellipsometer (Gaertner L2W16C830) with two wavelengths at $633 \mathrm{~nm}$ and $834.5 \mathrm{~nm}$ and 49 points wafer scanning set-up. The film thickness was then checked with Tencor Alpha-step profiler 
500. The modulus and the hardness of thin films were quantitatively characterized from a load-displacement curve, using a nanoindenter (Triboscope ${ }^{\circledR}$, Hysitron Inc.) with quartz glass as a reference. The films of about 1 micron in thickness were employed in order to avoid the substrate effect, and the values at $5 \%$ of the total film thickness are reported in this study.

Poly(methylsilsesquioxane) 1. PMSSQ was prepared by a hydrolysis-condensation reaction. To $6.81 \mathrm{~g}$ (0.05 mol) methyltrimethoxysilane (MTMS), cooled in an ice-bath, a solution of $1 \mathrm{~mL}(0.002 \mathrm{~mol}) 2 \mathrm{~m} \mathrm{HCl}$ in $9 \mathrm{~g}(0.5 \mathrm{~mol}) \mathrm{H}_{2} \mathrm{O}$ was added drop wise under stirring. The solution was afterwards stirred for $4 \mathrm{hrs}$ at $0{ }^{\circ} \mathrm{C}$. The solution was then diluted with $75 \mathrm{~mL}$ methyl-isobutylketone (MIBK). After washing at least 3 times with water, until neutral $\mathrm{pH}$, the organic phase was dried with $\mathrm{MgSO}_{4}$, filtered and solvent was evaporated in vacuum. The product obtained after vacuum-drying was a colorless solid (3.05 g) and it was stored at $-20{ }^{\circ} \mathrm{C}$. Selected characterization data: ${ }^{1} \mathrm{H}$ NMR $(300 \mathrm{MHz}$, d6-acetone): 6.2 - 5.4 ( $\mathrm{Si}-\mathrm{OH}), 3.5\left(\mathrm{Si}-\mathrm{OCH}_{3}\right), 0.13\left(\mathrm{Si}^{-} \mathrm{CH}_{3}\right)$.

2-Bromo-isobutyroic acid pent-4-enylate 2. To a solution of $6.89 \mathrm{~g}(0.08 \mathrm{~mol})$ 4pentenol in Chloroform an aliquot of triethylamine as added. Then a solution of $18.4 \mathrm{~g}$ (0.08 mol) 2-bromoisobutyryl acid bromide in $50 \mathrm{~mL}$ chloroform was drop wise added at $0^{\circ} \mathrm{C}$. The solution was then stirred for $4 \mathrm{hrs}$ at room temperature. The organic phase was washed 3 times with water, dried over $\mathrm{MgSO}_{4}$ and filtered. The solvent was then evaporated in vacuum. The pure product could be obtained by vacuum distillation (yield 13.6 g, 72 \%). Selected characterization data: ${ }^{1} \mathrm{H}$ NMR (300 MHz, $\left.\mathrm{CDCl}_{3}\right): 5.81$ (m, $1 \mathrm{H}$, 
$\mathrm{CH}=\mathrm{CH}_{2}$ ), 5.05 (m, $2 \mathrm{H}, \mathrm{CH}=\mathrm{CH}_{2}$ ), 4.15 (t, $\left.2 \mathrm{H}, \mathrm{O}-\mathrm{CH}_{2}-\right), 2.15$ (q, $\left.2 \mathrm{H}, \mathrm{CH}_{2}-\mathrm{CH}=\right), 1.90$

(s, $\left.6 \mathrm{H},-\mathrm{CH}_{3}\right), 1.78$ (p, $\left.2 \mathrm{H}, \mathrm{CH}_{2}-\mathrm{CH}_{2}-\mathrm{CH}_{2}\right) .{ }^{13} \mathrm{C}$ NMR: $171.8(\mathrm{C}=\mathrm{O}), 137.6\left(\mathrm{CH}=\mathrm{CH}_{2}\right)$, $115.8\left(\mathrm{CH}=\mathrm{CH}_{2}\right), 65.6\left(\mathrm{O}-\mathrm{CH}_{2}\right), 56.2(\mathrm{C}-\mathrm{Br}), 30.2\left(\mathrm{CH}_{2}\right), 27.8\left(\mathrm{CH}_{3}\right)$.

2-Bromo-isobutyroic acid 5-(chlorodimethylsilanyl)-pentyl ester 3. In a dry flask 100 mg platinum on carbon (10 wt\%) is weighed in a glove box. Into the flask $20 \mathrm{~mL}$ dry toluene, $2 \mathrm{~mL}$ ( $2.54 \mathrm{~g}, 0.011 \mathrm{~mol})$ of 2 and $6 \mathrm{~mL}$ dimethylchlorosilane were added via syringe. The solution was stirred at $65{ }^{\circ} \mathrm{C}$ for 24 hrs. After filtration over celite, toluene was evaporated. The pure product was obtained by vacuum distillation (yield $1.9 \mathrm{~g}$, $0.0058 \mathrm{~mol}, 53$ \%). Selected characterization data: ${ }^{1} \mathrm{H}$ NMR (300 MHz, $\left.\mathrm{CDCl}_{3}\right): 4.14$ (t, $2 \mathrm{H}, \mathrm{O}-\mathrm{CH}_{2}$ ), 1.89 (s, $\left.6 \mathrm{H},-\mathrm{CH}_{3}\right), 1.67$ (m, $\left.2 \mathrm{H}, \mathrm{O}-\mathrm{CH}_{2}-\mathrm{CH}_{2}\right), 1.41$ (m, $\left.4 \mathrm{H}, \mathrm{CH}_{2}\right), 0.80$ (t, $2 \mathrm{H}, \mathrm{CH}_{2}$-Si), 0.37 (s, $6 \mathrm{H}$, Si-CH$\left.)_{3}\right){ }^{13} \mathrm{C}$ NMR: $171.7(\mathrm{C}=\mathrm{O}), 66.0\left(\mathrm{O}-\mathrm{CH}_{2}\right), 56.0(\mathrm{C}-\mathrm{Br})$, 30.8 $\left(\mathrm{CH}_{2}\right), 29.2\left(\mathrm{CH}_{2}\right), 28.1\left(\mathrm{CH}_{3}\right), 22.7\left(\mathrm{CH}_{2}\right), 18.9\left(\mathrm{Si}-\mathrm{CH}_{2}\right), 1,7\left(\mathrm{Si}-\mathrm{CH}_{3}\right)$.

General procedure for the functionalization of PMSSQ. In $10 \mathrm{~mL}$ dry THF $500 \mathrm{mg}$ PMSSQ 1 are dissolved. Triethylamine is added via syringe. The solution is cooled in an ice-bath and then a desired amount of $\mathbf{3}$ is added drop wise. The solution is then stirred for $3 \mathrm{hrs}$ at room temperature. Following, the solution is diluted with $40 \mathrm{~mL}$ MIBK and washed with water. The organic phase is dried over $\mathrm{MgSO}_{4}$, filtered and the solvent is evaporated in vacuum. The product is stored at $-20{ }^{\circ} \mathrm{C}$. Selected characterization data: ${ }^{1} \mathrm{H}$ NMR (300 MHz, $\left.\mathrm{CDCl}_{3}\right)$ : 6.2 - $5.4(\mathrm{Si}-\mathrm{OH}), 3.5\left(\mathrm{Si}-\mathrm{OCH}_{3}\right), 4.14\left(\mathrm{O}-\mathrm{CH}_{2}\right), 1.89\left(-\mathrm{CH}_{3}\right)$, $1.67\left(\mathrm{O}-\mathrm{CH}_{2}-\mathrm{CH}_{2}\right), 1.41\left(\mathrm{CH}_{2}\right), 0.80\left(\mathrm{CH}_{2}-\mathrm{Si}\right), 0.37\left(\mathrm{Si}-\mathrm{CH}_{3}\right), 0.13\left(\mathrm{Si}-\mathrm{CH}_{3}\right)$. 
General procedure for the solution ATRP of methyl methacrylate. Methyl methacrylate, $\mathrm{CuBr}$ and 2,2'-bipyridine were dissolved in dry THF in a flask. The reaction flask was degassed by purging $\mathrm{N}_{2}$ for 5 minutes through the solution. In another small flask the initiator 4 was dissolved in THF and degassed by purging $\mathrm{N}_{2}$ for 5 minutes through the solution. Then the initiator solution was added via syringe to the monomer solution and stirred at $60{ }^{\circ} \mathrm{C}$ for an appropriate time. The polymer solution was filtered over basic $\mathrm{Al}_{2} \mathrm{O}_{3}$ and the polymer was precipitated in hexane. After reprecipitation from THF into hexane, the polymer was dried in vacuum. 